\title{
Genetic and clinical aspects of Zellweger spectrum patients with PEX1 mutations
}

\author{
H Rosewich, A Ohlenbusch, J Gärtner
}

J Med Genet 2005;42:e58 (http://www.jmedgenet.com/cgi/content/full/42/9/e58). doi: 10.1136/jmg.2005.033324

\begin{abstract}
Objective: To analyse the PEXI gene, the most common cause for peroxisome biogenesis disorders (PBD), in a consecutive series of patients with Zellweger spectrum.

Methods: Mutations were detected by different methods including SSCP analyses as a screening technique on the basis of genomic or CDNA, followed by direct sequencing of PCR fragments with an abnormal electrophoresis pattern.

Results: 33 patients were studied. Two common mutations, c.2528G $\rightarrow$ A, G843D and c.2098_2098insT, 1700YfsX42, accounted for over $80 \%$ of all abnormal PEXI alleles, emphasising their diagnostic relevance. Most PEX1 mutations were distributed over the two AAA cassettes with the two functional protein domains, D1 and D2, and the highly conserved Walker motifs. Phenotypic severity of Zellweger spectrum in CG1 depended on the effect of the mutation on the PEXI protein, peroxin 1. PEXI mutations could be divided into two classes of genotype-phenotype correlation: class I mutations led to residual PEXI protein levels and function and a milder phenotype; class II mutations almost abolished PEX1 protein levels and function, resulting in a severe phenotype. Compound heterozygote patients for a class I and class II mutation had an intermediate phenotype. Conclusions: Molecular confirmation of the clinical and biochemical diagnosis will allow the prediction of the clinical course of disease in individual PBD cases.
\end{abstract}

$\mathrm{P}$ eroxisomes are ubiquitous components of eukaryotic cells. Metabolic functions of these organelles are widespread and include hydrogen peroxide based respiration, $\beta$ oxidation of very long chain fatty acids (VLCFA), and biosynthesis of ether phospholipids, bile acids, and isoprene compounds. ${ }^{1}$ Several human diseases are caused by mutations in genes encoding peroxisomal metabolic enzymes, ${ }^{2}$ but the most dramatic loss of peroxisome function is observed in the peroxisome biogenesis disorders (PBD; MIM 601539). ${ }^{3}$

For PBD two broad clinical spectra can be distinguished, the Zellweger spectrum, accounting for about $80 \%$ of all PBD patients, and the rhizomelia chondrodysplasia punctata (RCDP) spectrum. ${ }^{3}{ }^{4}$ The Zellweger spectrum consists of three overlapping clinical phenotypes that represent a continuum of disease severity, including Zellweger syndrome (MIM 214100) as the prototype and most severe example of this group, neonatal adrenoleucodystrophy (NALD, MIM 202370) as an intermediate form, and infantile Refsum disease (IRD, MIM 266510) as the mildest variant. Zellweger syndrome patients have characteristic dysmorphic features, severe neurological dysfunction including hypotonia, seizures and poor feeding; they have eye abnormalities like cataracts, liver dysfunction and skeletal defects. They rarely survive the first year of life. Patients with NALD, IRD and atypical Zellweger syndrome have similar but less severe clinical signs and can survive up to several decades. RCDP is clinically and genetically distinctive from the Zellweger syndrome spectrum and includes classical RCDP as the prototype and also milder variants. Patients with classical RCDP have unique clinical symptoms including proximal shortening of the limbs (rhizomelia), cataracts, and profound psychomotor retardation.

PBDs can be caused by defects in any of several processes in organelle formation, including the synthesis of peroxisome membranes, the recognition of newly synthesised peroxisomal matrix proteins, or any of the downstream steps in peroxisomal protein import. Progress over the last two decades has led to the identification of 13 different human $P E X$ genes involved in peroxisome biogenesis, explaining the primary genetic defect of all 13 known complementation groups (CG) for PBD patients. The defective genes are PEXI for CG1 $1,{ }^{5}$ PEXS for CG2, ${ }^{7}$ PEXI2 for CG $3,{ }^{89}$ PEX6 for CG4, ${ }^{10}$ PEXI0 for CG7,,$^{11}{ }^{12}$ PEX26 for CG8, ${ }^{13}$ PEXI6 for CG9, ${ }^{14}$ PEX2 for CG10, ${ }^{15}$ PEX7 for CG11, ${ }^{16}{ }^{17}$ PEX3 for CG12, ${ }^{18}$ PEXI3 for CG13, ${ }^{19} 20$ PEX19 for CG14, ${ }^{21}$ and PEXI4 for CGK. ${ }^{22}$ PEXI mutations are the most common cause and account for two thirds of all PBD patients.

PEX1 maps to 7q21-q22 and encodes peroxin l (PEX1), a $147 \mathrm{kDa}$ member of the AAA protein family of ATPases (ATPases associated with diverse cellular activities). PEXI is classified as a type II AAA ATPase as it comprises two ATPase domains (AAA cassettes) containing two functional domains D1 and D2, each spanning over about 200 amino acids (D1: 198 amino acids (p.436-633); D2: 185 amino acids (p.717$901)$ ) with the second one being highly conserved. ${ }^{23}$ Both AAA cassettes contain a Walker A and B motif (Walker Al and $\mathrm{B} 1$; Walker $\mathrm{A} 2$ and $\mathrm{B} 2$ ). ${ }^{24}$ Given that PEXl has not been crystallised completely, knowledge of the structure is limited. ${ }^{23}$ So far, only the structure of the $\mathrm{N}$ terminal domain is known. It shows striking similarity to that of two other type II AAA ATPases, namely valosin containing protein (VCP) and N-ethylmaleimide sensitive factor (NSF). VCP and NSF also seem to be involved in maintaining organelle function.

We analysed the PEXI gene in a consecutive series of 33 patients with Zellweger spectrum. We report the full spectrum of molecular defects in these patients as well as of those who have already been reported. We also describe the clinical features related to PEXI gene mutations and establish a genotype-phenotype correlation.

\section{METHODS}

The study included 168 Zellweger spectrum patients with PEXI mutations. Thirty three patients were analysed in our laboratory. The study was approved by the local university

Abbreviations: HGVS, Human Genome Variation Society; IRD, infantile Refsum disease; NSF, N-ethylmaleimide sensitive factor; NTD, N terminal domain; PBD, peroxisome biogenesis disorder; RCDP, rhizomelia chondrodysplasia punctata; VCP, valosin containing protein 
Table 1 Allele frequency regarding 288 mutant PEX Igenes from 168 patients

\begin{tabular}{|c|c|c|c|}
\hline cDNA level, protein level & Exon & Number of alleles & Allele frequency \\
\hline $\begin{array}{l}\text { Splice site mutations } \\
\text { c. } 1670+5 G \rightarrow T \\
\text { c. } 2071+1 G \rightarrow T \\
\text { c. } 2926+1 G \rightarrow A \\
\text { c. } 2926+2 T \rightarrow C \\
\text { c. } 3207+1 G \rightarrow C\end{array}$ & $\begin{array}{l}9 \\
\text { Intron 12, splice donor } \\
\text { Intron 18, splice donor } \\
\text { Intron 18, splice donor } \\
\text { Intron 20, splice donor }\end{array}$ & $\begin{array}{l}9 \\
2 \\
2 \\
3 \\
1 \\
1\end{array}$ & $\begin{array}{l}0.0313 \\
0.0069 \\
0.0069 \\
0.0104 \\
0.0035 \\
0.0035\end{array}$ \\
\hline 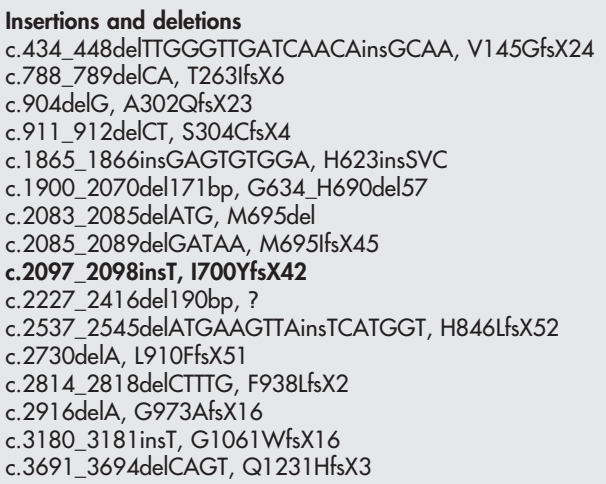 & $\begin{array}{l}4 \\
5 \\
5 \\
5 \\
11 \\
12 \\
13 \\
13 \\
13 \\
14 \\
15 \\
17 \\
18 \\
18 \\
20 \\
23\end{array}$ & $\begin{array}{l}134 \\
1 \\
1 \\
1 \\
1 \\
2 \\
1 \\
2 \\
1 \\
102 \\
3 \\
1 \\
4 \\
1 \\
10 \\
1 \\
2\end{array}$ & $\begin{array}{l}0.4653 \\
0.0035 \\
0.0035 \\
0.0035 \\
0.0035 \\
0.0069 \\
0.0035 \\
0.0069 \\
0.0035 \\
0.3542 \\
0.0104 \\
0.0035 \\
0.0139 \\
0.0035 \\
0.0347 \\
0.0035 \\
0.0069\end{array}$ \\
\hline $\begin{array}{l}\text { Nonsense mutations } \\
\text { c. } 781 \mathrm{C} \rightarrow \mathrm{T}, \mathrm{Q} 261 \mathrm{X} \\
\text { c. } 1897 \mathrm{C} \rightarrow \mathrm{T}, \mathrm{R} 633 \mathrm{X} \\
\text { c. } 2368 \mathrm{C} \rightarrow \mathrm{T}, \mathrm{R} 790 \mathrm{X} \\
\text { c. } 2383 \mathrm{C} \rightarrow \mathrm{T}, \mathrm{R} 795 \mathrm{X} \\
\text { c. } 2614 \mathrm{C} \rightarrow \mathrm{T}, \mathrm{R} 872 \mathrm{X} \\
\text { c. } 2992 \mathrm{C} \rightarrow \mathrm{T}, \mathrm{R} 998 \mathrm{X} \\
\text { c. } 3287 \mathrm{C} \rightarrow \mathrm{G}, \mathrm{S} 1096 \mathrm{X} \\
\text { c. } 3378 \mathrm{C} \rightarrow \mathrm{G}, \mathrm{Y} 1126 \mathrm{X}\end{array}$ & $\begin{array}{l}5 \\
11 \\
14 \\
14 \\
16 \\
19 \\
21 \\
21\end{array}$ & $\begin{array}{l}10 \\
1 \\
1 \\
1 \\
1 \\
3 \\
1 \\
1 \\
1\end{array}$ & $\begin{array}{l}0.0347 \\
0.0035 \\
0.0035 \\
0.0035 \\
0.0035 \\
0.0104 \\
0.0035 \\
0.0035 \\
0.0035\end{array}$ \\
\hline $\begin{array}{l}\text { Missense mutations } \\
\text { c. } 274 \mathrm{G} \rightarrow \mathrm{C}, \text { V92L } \\
\text { c. } 1777 \mathrm{G} \rightarrow \mathrm{A}, \mathrm{G} 593 \mathrm{R} \\
\text { c. } 1991 \mathrm{~T} \rightarrow \mathrm{C}, \mathrm{L} 664 \mathrm{P} \\
\text { c. } 2008 \mathrm{C} \rightarrow \mathrm{A}, \mathrm{L} 670 \mathrm{M} \\
\text { c. } 2387 \mathrm{C} \rightarrow \mathrm{C}, \mathrm{L} 796 \mathrm{P} \\
\text { c. } 2392 \mathrm{C} \rightarrow \mathrm{G}, \mathrm{R} 798 \mathrm{G} \\
\text { c. } 2528 \mathrm{G} \rightarrow \mathrm{A}, \mathrm{G} 843 \mathrm{D} \\
\text { c. } 2846 \mathrm{G} \rightarrow \mathrm{A}, \mathrm{R} 949 \mathrm{Q} \\
\text { c. } 3038 \mathrm{G} \rightarrow \mathrm{A}, \mathrm{R} 1013 \mathrm{H} \\
\text { c. } 3850 \mathrm{C} \rightarrow \mathrm{C}, \mathrm{X} 1284 \mathrm{Q}\end{array}$ & $\begin{array}{l}3 \\
10 \\
12 \\
12 \\
14 \\
14 \\
15 \\
18 \\
20 \\
24\end{array}$ & $\begin{array}{l}134 \\
2 \\
1 \\
1 \\
1 \\
1 \\
1 \\
124 \\
1 \\
1 \\
1\end{array}$ & $\begin{array}{l}0.4653 \\
0.0069 \\
0.0035 \\
0.0035 \\
0.0035 \\
0.0035 \\
0.0035 \\
0.4306 \\
0.0035 \\
0.0035 \\
0.0035\end{array}$ \\
\hline $\begin{array}{l}\text { Duplications } \\
\text { c.1951_1959dupCAGTGTGGA, W653_M654insTWW }\end{array}$ & 12 & $\begin{array}{l}1 \\
1\end{array}$ & $\begin{array}{l}0.0035 \\
0.0035\end{array}$ \\
\hline
\end{tabular}

ethics committee. Genomic DNA from cultured skin fibroblasts or leucocytes was used as template. Genomic DNA was obtained from leucocytes in 50 white controls. Mutations were detected by different methods including single strand conformation polymorphism (SSCP) analyses as a screening technique on the basis of genomic or cDNA, followed by direct sequencing of polymerase chain reaction (PCR) fragments with an abnormal electrophoresis pattern. ${ }^{525}{ }^{26}$ It is well known that SSCP analyses fail to detect $10-20 \%$ of mutations depending on fragment size and electrophoresis conditions. ${ }^{27}$ Thus we and others have also used reverse transcriptase PCR (RT-PCR) to amplify the coding sequence of PEXI, followed by direct sequencing, ${ }^{62428} 29$ or direct sequencing of PEXI exons that were amplified by PCR with intronic primers. ${ }^{30-33}$ For so far undescribed mutant alleles, polymorphism was excluded by analysing 100 white control alleles.

The mutation nomenclature used follows the recommendations of the Human Genome Variation Society (HGVS, http://www.genomic.unimelb.edu.au/mdi/rec.html). ${ }^{34}$ All mutations were adjusted to mRNA reference sequence NM_000466 (version: NM_000466.1; source sequence:
AF026086; version: AF026086.1; protein product: NP_000457; version: NP_000457.1).

\section{RESULTS AND DISCUSSION}

Mutation data analyses from 168 patients with 288 described mutant PEXI genes revealed 46\% missense mutations, $46 \%$ insertions and deletions, 3\% splice site mutations, 3\% nonsense mutations, and $0.3 \%$ duplications (table 1 ).

Table 2 summarises all currently known PEXI mutations as well as the available clinical phenotypes.

The most common PEXI mutation, with an allele frequency of 0.43 , is c. $2528 \mathrm{G} \rightarrow \mathrm{A}, \mathrm{G} 843 \mathrm{D}$ in exon 15 . The second most common mutation is the insertion c.2097_2098insT, I700YfsX42, with an allele frequency of 0.35 . Thus these two common PEX1 mutations comprise about $80 \%$ of all abnormal alleles in CG1. The vast majority of PEXI mutations are distributed over the two AAA cassettes with the functional protein domains, D1 and D2, and the highly conserved Walker motifs (fig 1).

c. $2528 \mathrm{G} \rightarrow \mathrm{A}, \mathrm{G} 843 \mathrm{D}$ is localised in the second functional domain (D2). c.2097_2098insT, I700YfsX42 is localised before the second functional domain, resulting in a truncated 


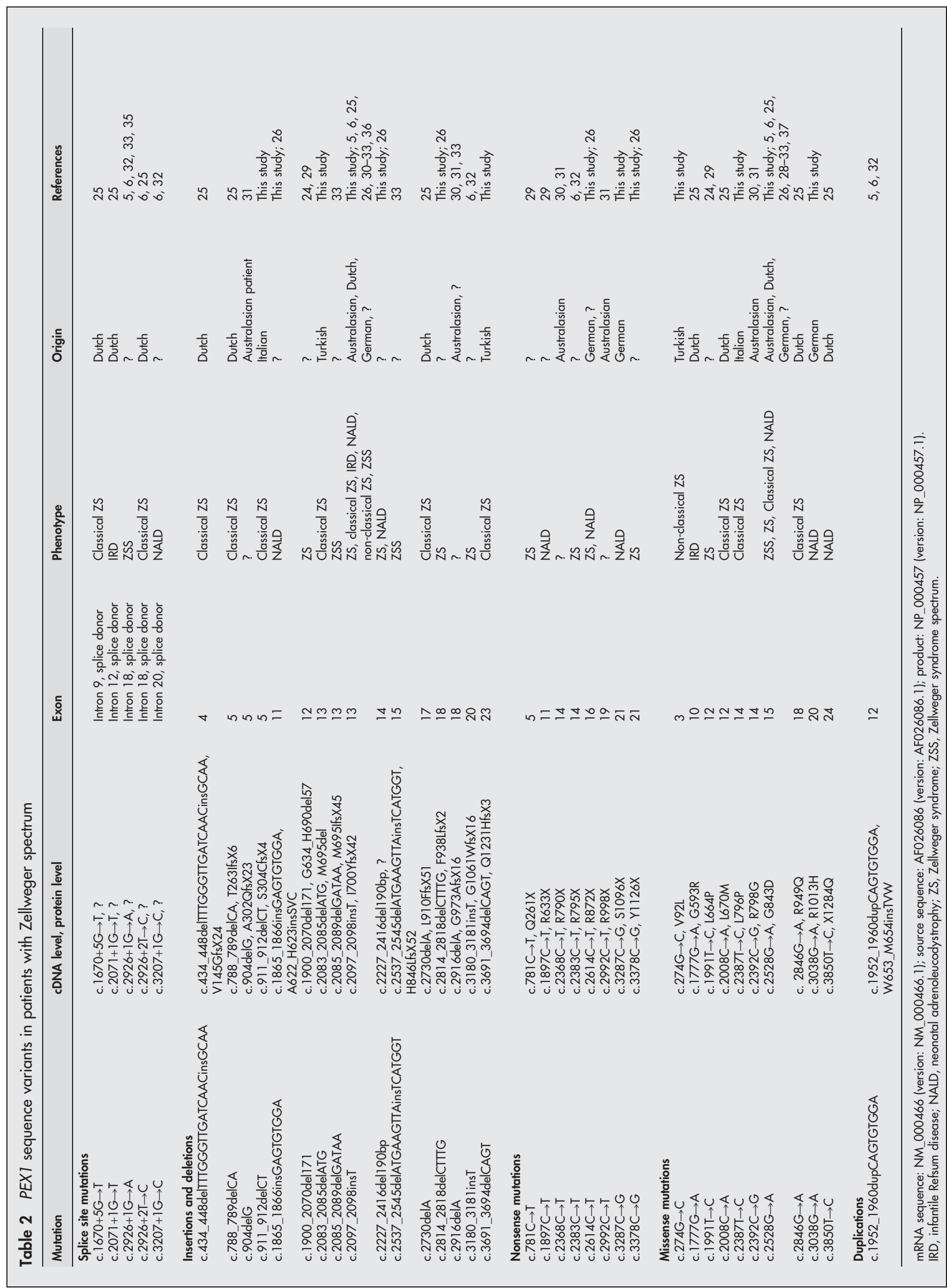




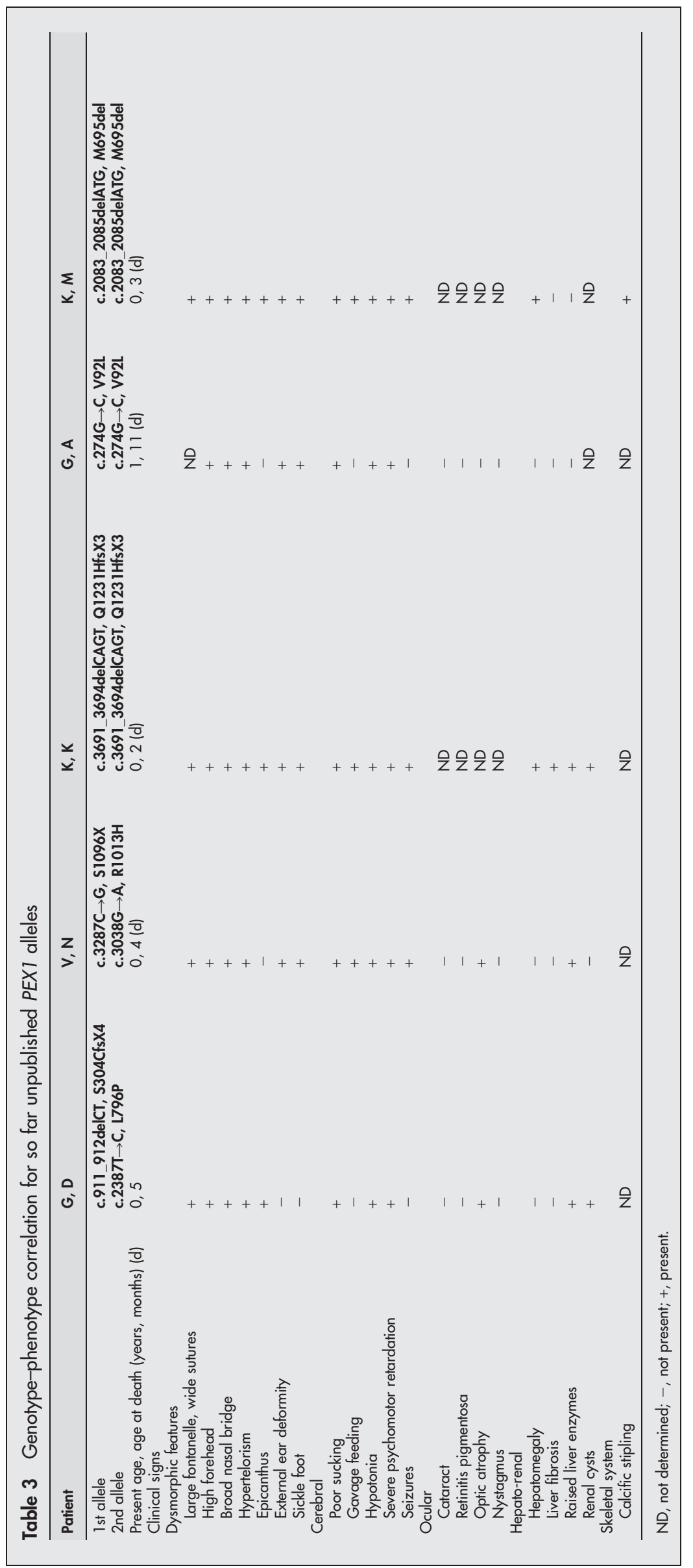




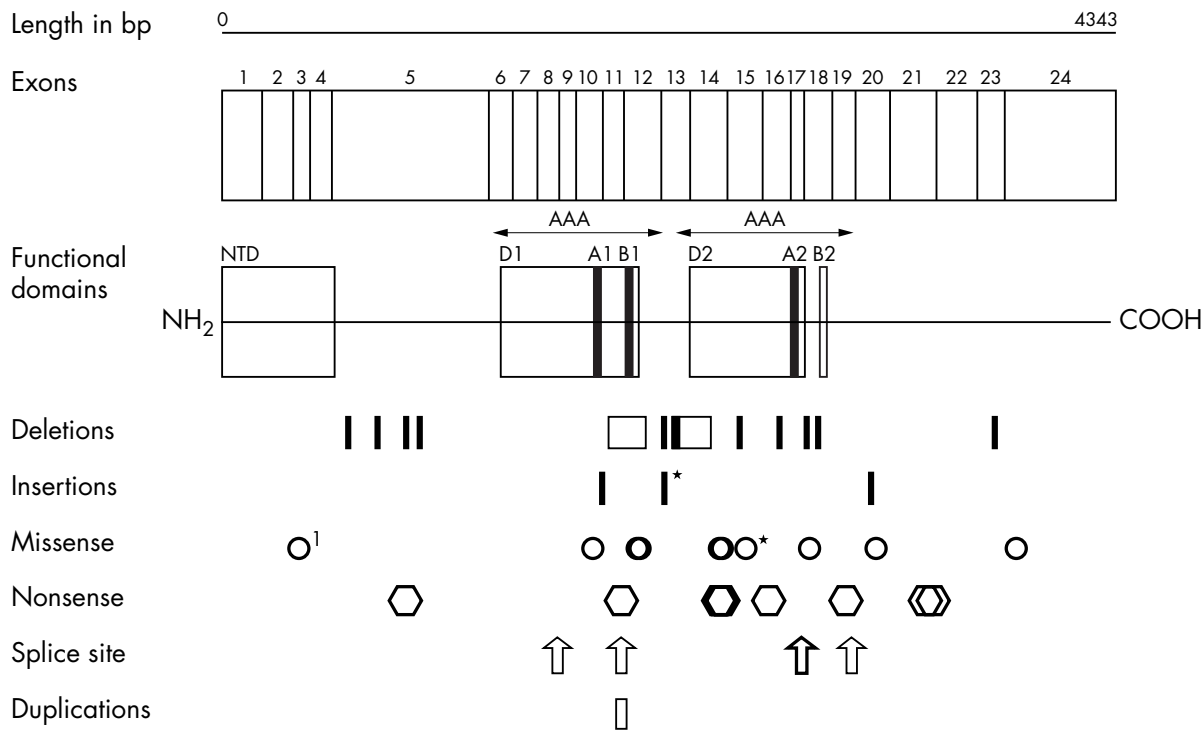

Figure 1 Distribution of PEX1 mutations over the functional protein domains. The protein has two AAA domains (AAA) with two functional domains, $D 1$ and D2, and the highly conserved Walker $A$ and $B$ motifs (A1, B1, A2, B2). Asterixes mark the two most common PEX1 mutations, c.2528G $\rightarrow A$, G843D and c.2097_2098insT, 1700YfsX42; ${ }^{1}=$ the first mutation identified in the crystallised NTD. NTD, N-terminal domain.

protein containing only one of the two nucleotide binding folds. In this study we identified seven mutations that have not been described so far-namely, c.911_912delCT, S304CfsX4; c.2083_2085delATG, M695del; c.3691_ 3694delCAGT, Q1231HfsX3; c.3287C $\rightarrow$ G, S1096X; c. $274 \mathrm{G} \rightarrow \mathrm{C}, \quad$ V92L; c.2387T $\rightarrow$ C, L796P; and $\quad$ c.3083G $\rightarrow$ A, $\mathrm{R} 1013 \mathrm{H}$. c. $274 \mathrm{G} \rightarrow \mathrm{C}$. V92L is the first mutation that has been detected in the crystallised NTD.

Mutations in the PEXI gene are the most common cause of peroxisome biogenesis disorders. ${ }^{6}$ Alterations in this gene can lead to different clinical phenotypes comprising a continuum from severely affected patients with classical Zellweger syndrome through neonatal adrenoleucodystrophy, to infantile Refsum disease as the least severe. A summary of the data on genotype-phenotype correlations, including those already published and those derived from our own study (tables 2 and 3), confirms that there is a close link between the cellular impact of particular PEXI mutations and the severity of the clinical course.

Class I mutations result in a peroxin 1 with residual protein levels and function, while class II mutations abolish PEXI protein levels and function. Class I mutations are missense mutations, with c.2528G $\rightarrow$ A, G843D being by far the most frequent allele. c. $2528 \mathrm{G} \rightarrow \mathrm{A}, \mathrm{G} 843 \mathrm{D}$ is a temperature sensitive mutation leading to reduced protein levels and function. ${ }^{25} 31$ c. $2528 \mathrm{G} \rightarrow \mathrm{A}, \mathrm{G} 843 \mathrm{D}$ on both alleles results in PEXI protein levels of 3 to $20 \%$ compared to wild type. Other missense mutations like c.2392C $\rightarrow \mathrm{G}, \mathrm{R} 798 \mathrm{G}$ that affects the first conserved functional protein domain Dl shows comparable PEX 1 protein levels and activity. ${ }^{31}$ Interaction of PEX1 with the second AAA-ATPase involved in peroxisome biogenesis, PEX6, in patients carrying c. $2528 \mathrm{G} \rightarrow \mathrm{A}, \mathrm{G} 843 \mathrm{D}$ alleles is reduced by $70 \%$ when compared to wild type. ${ }^{38}$ The most common class II mutation is c.2097_2098insT, I700YfsX42 resulting in a truncated PEXI protein with a complete loss of the second functional domain, D2. In cells from CG1 patients bearing this mutation or other class II mutations including insertions, deletions, and splicing mutations, there is a total or nearly total loss of protein levels and function. ${ }^{25}{ }^{30}$ Patients with a class I mutation on both alleles present with a milder disease course, while those with class II mutation have a severe clinical phenotype. Patients who are compound heterozygotes for a class I and class II mutation (for example, c.2528G $\rightarrow$ A， G843D / c.2097_2098insT, I700YfsX42; c. $2071+\mathrm{lG} \rightarrow \mathrm{T} / \mathrm{c} .1777 \mathrm{G} \rightarrow \mathrm{A}, \mathrm{G} 593 \overline{\mathrm{R}}$ ) show an intermediate clinical phenotype. ${ }^{25} 26$

The incomplete knowledge of peroxisome biogenesis in general and of the pathophysiology in Zellweger spectrum patients and other PBDs hampers the attempts at devising effective treatments. The combined approach of functional studies in vitro and in mouse models with conditional alleles in vivo, as well as studying human cellular and clinical phenotypes, should further improve our understanding of the role of peroxins including PEXl protein in peroxisome assembly. As the milder PBD phenotypes correlate with an unstable mutant protein with some residual function, treatment directing towards the identification of peroxisome associated factors that regulate protein stability of mutant PEXl proteins might be a useful approach to reduce the severity of the disease.

\section{Conclusions}

PEXI mutations are the major primary cause of Zellweger spectrum. These conditions include, in decreasing order of clinical severity, Zellweger syndrome, neonatal adrenoleucodystrophy, and infantile Refsum disease. In a given patient the degree of phenotypic severity correlates closely with the functional consequences of the PEXI mutation on the encoded protein. In clinical practice, having a molecular confirmation of the clinical and biochemical diagnosis allows prediction of the clinical course of the disease in individual PBD cases. Furthermore, knowing the PEXI mutation in an affected family is the only way to identify carriers. It ensures accurate genetic counselling and prenatal diagnosis on DNA based mutation detection techniques to identify the genotype of a fetus at risk.

\section{DATABASES}

PEXI - OMIM: No 214100, 602136; GenBank: AC000064 (Homo sapiens, BAC clone), AF026086, AF030356, AB008112 and BC035575 (Homo sapiens, mRNA), AB052090 (Homo sapiens, mRNA for Pexlp-634del690), AB052091 (Homo sapiens, mRNA for PexlpL664P), AB052092 (Homo sapiens, mRNA for PexlpG843D), AB052093 (Homo sapiens, mRNA for 
PexlpR633Ter), AB052094 (Homo sapiens, mRNA for PexlpQ261Ter), CH236949 (Homo sapiens, genomic sequence).

\section{ACKNOWLEDGEMENTS}

This work was supported by the Deutsche Forschungsgemeinschaft (DFG), grant number GA 354/5-1 and 354/5-2.

\section{Authors' affiliations}

H Rosewich, J Gärtner, A Ohlenbusch, Department of Paediatrics and Paediatric Neurology, Georg August University, Göttingen, Germany

Competing interests: none declared

Correspondence to: Dr Jutta Gärtner, Department of Paediatrics and Paediatric Neurology, Georg August University, Robert-Koch-Strasse 40, 37075 Göttingen, Germany; gaertnj@med.uni-goettingen.de

Revised version received 5 May 2005

Accepted for publication 9 May 2005

\section{REFERENCES}

1 Wanders RJ. Metabolic and molecular basis of peroxisomal disorders: a review. Am J Med Genet 2004;126A:355-75.

2 Wanders RJ, Tager JM. Lipid metabolism in peroxisomes in relation to human disease. Mol Aspects Med 1998;19:69-154.

3 Gould SJ, Raymond GV, Valle D. The peroxisome biogenesis disorders. In: Scriver CR, Beaudet AL, Sly WS, Valle D, eds. The metabolic and molecular bases of inherited disease. New York: McGraw-Hill Information Services Company, 2001:3181-217.

4 Brosius U, Gartner J. Cellular and molecular aspects of Zellweger syndrome and other peroxisome biogenesis disorders. Cell Mol Life Sci 2002:59:1058-69.

5 Portsteffen H, Beyer A, Becker E, Epplen C, Pawlak A, Kunau WH, Dodt G. Human PEX 1 is mutated in complementation group 1 of the peroxisome biogenesis disorders. Nat Genet 1997;17:449-52.

6 Reuber BE, Germain-Lee E, Collins CS, Morrell JC, Ameritunga R, Moser HW, Valle D, Gould SJ. Mutations in PEXI are the most common cause of peroxisome biogenesis disorders. Nat Genet 1997;17:445-8.

7 Dodt G, Braverman N, Wong C, Moser A, Moser HW, Watkins P, Valle D, Gould SJ. Mutations in the PTS1 receptor gene, PXR1, define complementation group 2 of the peroxisome biogenesis disorders. Nat Genet 1995;9:115-25.

8 Chang CC, Lee WH, Moser H, Valle D, Gould SJ. Isolation of the human PEX12 gene, mutated in group 3 of the peroxisome biogenesis disorders. Nat Genet 1997; 15:385-8.

9 Okumoto K, Shimozawa N, Kawai A, Tamura S, Tsukamoto T, Osumi T, Moser H, Wanders RJ, Suzuki Y, Kondo N, Fujiki Y. PEX12, the pathogenic gene of group III Zellweger syndrome: cDNA cloning by functional complementation on a CHO cell mutant, patient analysis, and characterization of PEX12p. Mol Cell Biol 1998;18:4324-36.

10 Fukuda S, Shimozawa N, Suzuki Y, Zhang Z, Tomatsu S, Tsukamoto T, Hashiguchi N, Osumi T, Masuno M, Imaizumi K, Kuroki Y, Fujiki Y, Orii T, Kondo N. Human peroxisome assembly factor-2 (PAF-2): a gene responsible for group $\mathrm{C}$ peroxisome biogenesis disorder in humans. Am J Hum Genet 1996;59:1210-20.

11 Warren DS, Morrell JC, Moser HW, Valle D, Gould SJ. Identification of PEX10, the gene defective in complementation group 7 of the peroxisomebiogenesis disorders. Am J Hum Genet 1998;63:347-59.

12 Okumoto K, Itoh R, Shimozawa N, Suzuki Y, Tamura S, Kondo N, Fujiki Y. Mutations in PEX10 is the cause of Zellweger peroxisome deficiency syndrome of complementation group B. Hum Mol Genet 1998;7:1399-405.

13 Matsumoto N, Tamura S, Furuki S, Miyata N, Moser A, Shimozawa N, Moser HW, Suzuki Y, Kondo N, Fujiki Y. Mutations in novel peroxin gene PEX26 that cause peroxisome-biogenesis disorders of complementation group 8 provide a genotype-phenotype correlation. Am J Hum Genet 2003:73:233-46.

14 South ST, Gould SJ. Peroxisome synthesis in the absence of preexisting peroxisomes. J Cell Biol 1999;144:255-66.

15 Shimozawa N, Tsukamoto T, Suzuki Y, Orii T, Shirayoshi Y, Mori T, Fujiki Y. A human gene responsible for Zellweger syndrome that affects peroxisome assembly. Science 1992;255:1132-4.

16 Braverman N, Steel G, Obie C, Moser A, Moser H, Gould SJ, Valle D. Human PEX7 encodes the peroxisomal PTS2 receptor and is responsible for rhizomelic chondrodysplasia punctata. Nat Genet 1997;15:369-76.
17 Purdue PE, Zhang JW, Skoneczny M, Lazarow PB. Rhizomelic chondrodysplasia punctata is caused by deficiency of human PEX7, a homologue of the yeast PTS2 receptor. Nat Genet 1997;15:381-4.

18 South ST, Sacksteder KA, Li X, Liu Y, Gould SJ. Inhibitors of COPI and COPII do not block PEX3-mediated peroxisome synthesis. J Cell Biol 2000;149:1345-60

19 Shimozawa N, Suzuki Y, Zhang Z, Imamura A, Toyama R, Mukai S, Fujiki Y, Tsukamoto T, Osumi T, Orii T, Wanders RJ, Kondo N. Nonsense and temperature-sensitive mutations in PEX13 are the cause of complementation group $\mathrm{H}$ of peroxisome biogenesis disorders. Hum Mol Genet 1999;8: 1077-83.

20 Liu Y, Bjorkman J, Urquhart A, Wanders RJ, Crane DI, Gould SJ. PEX13 is mutated in complementation group 13 of the peroxisome-biogenesis disorders. Am J Hum Genet 1999:65:621-34.

21 Matsuzono Y, Kinoshita N, Tamura S, Shimozawa N, Hamasaki M, Ghaedi K, Wanders RJ, Suzuki Y, Kondo N, Fujiki Y. Human PEX19: cDNA cloning by functional complementation, mutation analysis in a patient with Zellweger syndrome, and potential role in peroxisomal membrane assembly. Proc Natl Acad Sci USA 1999;96:2116-21.

22 Shimozawa N, Tsukamoto T, Nagase T, Takemoto Y, Koyama N, Suzuki Y, Komori M, Osumi T, Jeannette G, Wanders RJ, Kondo N. Identification of a new complementation group of the peroxisome biogenesis disorders and PEX14 as the mutated gene. Hum Mutat 2004;23:552-8.

23 Shiozawa K, Maita N, Tomii K, Seto A, Goda N, Akiyama Y, Shimizu T, Shirakawa M, Hiroaki $H$. Structure of the N-terminal domain of PEXI AÁAATPase. Characterization of a putative adaptor-binding domain. J Biol Chem 2004; 279:50060-8

24 Tamura S, Okumoto K, Toyama R, Shimozawa N, Tsukamoto T, Suzuki Y, Osumi T, Kondo N, Fujiki Y. Human PEXI cloned by functional complementation on a $\mathrm{CHO}$ cell mutant is responsible for peroxisomedeficient Zellweger syndrome of complementation group I. Proc Natl Acad Sci USA 1998:95:4350-5.

25 Walter C, Gootjes J, Mooijer PA, Portsteffen H, Klein C, Waterham HR, Barth PG, Epplen JT, Kunau WH, Wanders RJ, Dodt G. Disorders of peroxisome biogenesis due to mutations in PEX1: phenotypes and PEX protein levels. Am J Hum Genet 2001;69:35-48.

26 Preuss N, Brosius U, Biermanns M, Muntau AC, Conzelmann E, Gartner J. PEX1 mutations in complementation group 1 of Zellweger spectrum patients correlate with severity of disease. Pediatr Res 2002;51:706-14.

27 Sheffield VC, Beck JS, Kwitek AE, Sandstrom DW, Stone EM. The sensitivity of single-strand conformation polymorphism analysis for the detection of single base substitutions. Genomics 1993;16:325-32.

28 Imamura A, Tamura S, Shimozawa N, Suzuki Y, Zhang Z, Tsukamoto T, Orii T, Kondo N, Osumi T, Fujiki Y. Temperature-sensitive mutation in PEX1 moderates the phenotypes of peroxisome deficiency disorders. Hum Mol Genet 1998;7:2089-94

29 Tamura S, Matsumoto N, Imamura A, Shimozawa N, Suzuki Y, Kondo N, Fujiki Y. Phenotype-genotype relationships in peroxisome biogenesis disorders of PEX1-defective complementation group 1 are defined by Pex $1 \mathrm{p}$ Pex6p interaction. Biochem J 2001;357:417-26.

30 Maxwell MA, Nelson PV, Chin SJ, Paton BC, Carey WF, Crane DI. A common PEX1 frameshift mutation in patients with disorders of peroxisome biogenesis correlates with the severe Zellweger syndrome phenotype. Hum Genet 1999; 105:38-44.

31 Maxwell MA, Allen T, Solly PB, Svingen T, Paton BC, Crane DI. Novel PEX1 mutations and genotype-phenotype correlations in Australasian peroxisome biogenesis disorder patients. Hum Mutat 2002;20:342-51.

32 Collins CS, Gould SJ. Identification of a common PEX1 mutation in Zellweger syndrome. Hum Mutat 1999;14:45-53.

33 Steinberg S, Chen L, Wei L, Moser A, Moser H, Cutting G, Braverman N. The PEX Gene Screen: molecular diagnosis of peroxisome biogenesis disorders in the Zellweger syndrome spectrum. Mol Genet Metab 2004;83:252-63.

34 den Dunnen JT, Antonarakis SE. Mutation nomenclature extensions and suggestions to describe complex mutations: a discussion. Hum Mutat 2000;15:7-12. Erratum in: Hum Mutat 2000;20:403

35 Chang CC, South S, Warren D, Jones J, Moser AB, Moser HW, Gould SJ. Metabolic control of peroxisome abundance. J Cell Sci 1999;112:1579-90.

36 Budden SS, Kennaway NG, Buist NR, Poulos A, Weleber RG. Dysmorphic syndrome with phytanic acid oxidase deficiency, abnormal very long chain fatty acids, and pipecolic acidemia: studies in four children. J Pediatr 1986; 108:33-9.

37 Heymans HS, van der Bosch H, Schutgens RB, Tegelaers WH, Walther JU, Muller-Hocker J, Borst P. Deficiency of plasmalogens in the cerebro-hepatorenal (Zellweger) syndrome. Eur J Pediatr 1984;142:10-15.

38 Geisbrecht BV, Collins CS, Reuber BE, Gould SJ. Disruption of a PEX1-PEX6 interaction is the most common cause of the neurologic disorders Zellweger syndrome, neonatal adrenoleukodystrophy, and infantile Refsum disease. Proc Natl Acad Sci USA 1998;21;95:8630-5. 